period, an exposure to an oxygen precursor, and another purge period." They said that "typical metal precursors include halides, alkyls, alkoxides, and betadiketonates, whereas water, hydrogen peroxide, ozone, and molecular oxygen have been used as an oxygen source." The problem with this approach, they said, is that the thin monolayer on top offers little protection against the oxidation of $\mathrm{Si}$ underneath.

As reported in the April 14 issue of Science, the scientists' chemical ALD approach seems to eliminate the direct oxygen source. The two-metal compound in which one is an alkoxide [M(OR $)_{n}$, where $\mathrm{M}=$ metal and $\mathrm{R}=$ alkyl group] produces a metal-oxide depositional layer without the $\mathrm{SiO}_{2}$ interlayer because the oxygen preferentially bonds with the metal.

The deposition of $\mathrm{Al}_{2} \mathrm{O}_{3}$ was accomplished by first etching $\mathrm{Si}$ with dilute $\mathrm{HF}$ so that native oxide could be removed. The metal-oxide compounds used for the deposition reaction were $\mathrm{Al}\left(\mathrm{CH}_{3}\right)_{3}$ and $\mathrm{Al}\left(\mathrm{OCH}\left(\mathrm{CH}_{3}\right)_{2}\right)_{3}$, with the latter being the metal alkoxide. The following reaction created the top oxide layer:

$$
\begin{gathered}
\mathrm{Al}\left(\mathrm{CH}_{3}\right)_{3}+\mathrm{Al}\left(\mathrm{OCH}\left(\mathrm{CH}_{3}\right)_{2}\right)_{3} \\
\mathrm{Al}_{2} \mathrm{O}_{3}+3 \mathrm{CH}_{3} \mathrm{CH}\left(\mathrm{CH}_{3}\right)_{2} .
\end{gathered}
$$

TEM imaging confirmed that the $\mathrm{SiO}_{2}$ interlayer was not produced. In addition, the scientists found that the activation temperature for these deposition reactions decreased as the branching of the alkyl group increased. They found deposition at elevated temperatures to be fast, steady, and economical.

JUNE LAU

\section{STM Utilized to Determine Structure at Atomic Scale}

H.J. Lee and W. Ho at the Laboratory of Atomic and Solid-State Physics at Cornell University have accomplished molecular synthesis, bond characterization, and molecular decompilation on the atomic scale with the use of a scanning tunneling microscope (STM). Their experiments, as reported in the June 15 issue of Physical Review B, consist of creating and destroying bonds between copper/iron and the carbonyl (CO) $)_{n}$ molecule(s).

Initially, a group of $\mathrm{Cu} / \mathrm{Fe}$ atoms and
CO molecules was scattered about on a $\operatorname{Ag}(110)$ substrate. The construction phase of these molecules consisted of "picking up" a CO molecule with the STM tip (at $250-\mathrm{mV}$ bias and 10-nA tunneling current), positioning the tip over a $\mathrm{Cu} / \mathrm{Fe}$ atom, and "letting go" of the CO molecule (with tip bias and tunneling current reduced to $70 \mathrm{mV}$ and $0.1 \mathrm{nA}$ ). Reversing the tip bias to $-70 \mathrm{mV}$ and, again, increasing the tunneling current to $10 \mathrm{nA}$ formed the bond between the $\mathrm{Cu} / \mathrm{Fe}$ atom and the $\mathrm{CO}$ molecule. Additional $\mathrm{CO}$ molecules were attached to the $\mathrm{Cu} / \mathrm{Fe}$ base in the same manner.

The first part of the characterization phase consisted of taking a topographical image of the compound. Symmetry of the $\mathrm{CuCO}$ molecule was noted, which suggests that the $\mathrm{C}-\mathrm{O}$ bond angle is perpendicular to the substrate surface. By contrast, FeCO exhibited two distinct configurations. Asymmetry in each of these configurations suggests that the $\mathrm{C}-\mathrm{O}$ bond in the Fe case deviates from the perpendicular by some angle $\tau$. These two configurations, however, are mirror images of each other

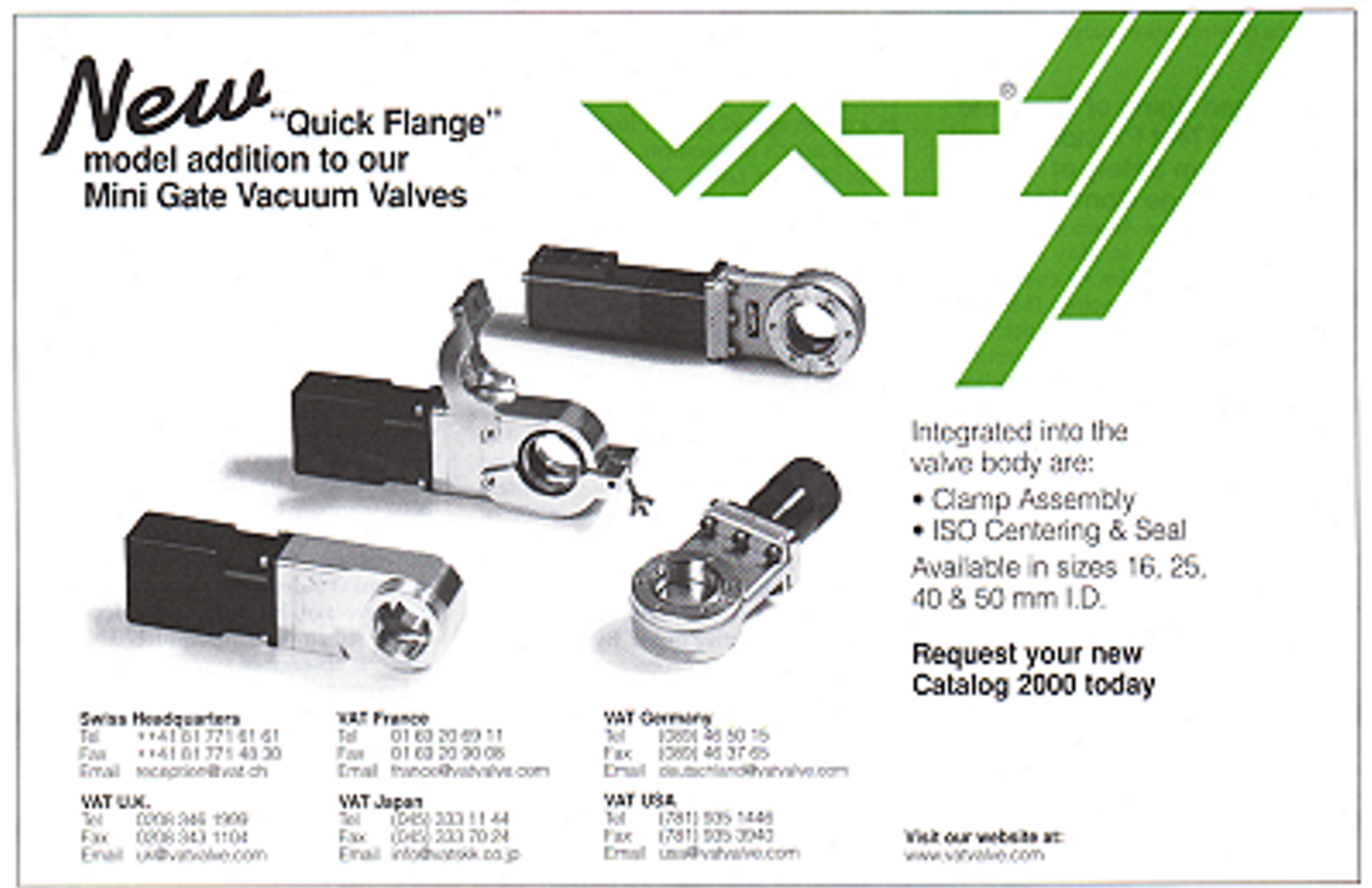

